\title{
Study of pH and Cellular Response in Pulmonary Fibroblasts After Exposure to Market Street World Trade Center Particulate Matter
}

\author{
Michelle Hernandez, Sung Choi and Ann Marie DiLorenzo \\ Department of Biology and Molecular Biology, \\ Montclair State University, 1 Normal Avenue, Montclair NJ
}

\begin{abstract}
Chronic health conditions have been noted among first responders and residents exposed to the dust generated from the World Trade Center (WTC) collapse on September 11, 2001. This study sought to isolate a single factor thought to play a substantial role in the decreased lung function of World Trade Center (WTC) workers and victims. Human pulmonary fibroblasts were exposed to 0 (control), 2.5, 25, 250 $\mathrm{mg} \mathrm{mL} \mathrm{m}^{-1}$ WTC dust at $5 \% \mathrm{CO}_{2}$ and $10 \% \mathrm{CO}_{2}$ to test the hypothesis that cellular toxicity is attributed to the high $\mathrm{pH}$ (9.3) of the WTC dust. A decrease in viability, increase in toxicity, as well as increased apoptotic activity with increased WTC dust exposure at $5 \% \mathrm{CO}_{2}$ were observed $24 \mathrm{~h}$ post exposure Exposure of cells under $10 \% \mathrm{CO}_{2}$, which reduced the high $\mathrm{pH}$ of the media, significantly increased viability, as well as decreased toxicity and apoptotic activity. Our results show that cellular toxicity can be mitigated by reducing the $\mathrm{pH}$ of the exposure condition and that high alkalinity is one of the most important factors in producing cellular toxicity in vitro.
\end{abstract}

Keywords: WTC, Airborne Particulates, Particles, Human Lung Fibroblast Cells, Proliferate, Apoptosis, Mutagen, Toxin

\section{INTRODUCTION}

In the aftermath of the collapsed twin towers, many first responders and rescue workers were exposed to the fallout dust. Those who were exposed to higher concentrations of WTC dust quickly began to exhibit irritation of the eyes, nose and throat brought on by Volatile Organic Compounds (VOC) USEPA, 2003. Studies have found the main components of WTC $\mathrm{PM}_{2.5}$ to include but not limited to concrete, cement aggregate, ceiling tiles and wallboard (Lioy et al., 2002; McGee et al., 2003). Cellulose from insulation accounts for $20 \%$ of the dry bulk mass and many forms are known to be bio-resistant as well as bio-persistent (Pauly et al., 1998). Glass fibers also account for the bulk of the samples tested and are also known injury inducers having been linked to sarcoidosis, a granulomatous disease known to have affected many of the WTC first responders (Izbicki et al., 2007).

The $\mathrm{pH}$ of the WTC dust was determined to be between 9.2-11.5, well above physiological standards of $7.2 \pm 0.5$ and perhaps the source of mucous membrane irritation and the "World Trade Center cough" (Chen and Thurston, 2002; Thurston and Chen, 2002). Quick changes in $\mathrm{pH}$ can be detrimental to cellular activity as compared to that of slower $\mathrm{pH}$ change over time and may induce apoptotic activity leading to cell death (Terminella et al., 2002). It was thought that the inflammatory response due to the caustic nature of the dust may only have been a temporary symptom due to the fact that as particles become smaller, they become less caustic, but toxicity is dependent on the makeup of the particle (Chen and Thurston, 2002).

Corresponding Author: Ann Marie DiLorenzo, Department of Biology and Molecular Biology, Montclair State University, 1 Normal Avenue, Montclair NJ 


\section{MATERIALS AND METHODS}

\subsection{Dust Sample}

The WTC dust sample was obtained from Dr. Paul Lioy at Rutgers University. The main components of WTC $\mathrm{PM}_{2.5}$ include but are not limited to concrete, cement aggregate, ceiling tiles, wallboard and glass fibers (Lioy et al., 2002; McGee et al., 2003; Izbicki et al., 2007).

\subsection{Media Preparation}

Stock WTC dust solutions were prepared using Eagle's Minimal Essential Media (MEM), 10\% Fetal Bovine Serum (FBS) and 1\% of Penicillin Streptomycin (PS), Kanamycin Sulfate (K) and Glutamax (G). The WTC dust sample was exposed to UV radiation for $24 \mathrm{~h}$ for sterilization and weighed accordingly to make a 1000 $\mathrm{mg} \mathrm{mL}^{-1}$ stock solution. From the stock solution, dilutions were calculated and stored at $-18^{\circ} \mathrm{C}$.

\subsection{Cell Culture Maintenance}

MRC-5 (ATCC-CCL 171) human pulmonary fibroblast cells were cultured in Eagle's MEM and 10\% FBS containing 1\% PSKG. Cells were plated into T-25 flasks and sub-cultured by scraping with reintroduction to $6 \mathrm{~mL}$ of MEM/10\% FBS solution in fresh T-25 flasks. Cells were incubated at $37^{\circ} \mathrm{C}$ in an incubator at $5 \% \mathrm{CO}_{2}$.

\section{4. pH Calculations of Media and WTC Dust in Media}

$\mathrm{pH}$ of the MEM/10\%FBS/PSKG and WTC dust solutions were measured using an IQ Scientific "Dual Technology" $\mathrm{pH}$ meter. Plain media and WTC dust media solutions were measured at three different time points at $5 \% \mathrm{CO}_{2}$ and $10 \% \mathrm{CO}_{2}$ to check for fluctuations in $\mathrm{pH}$ change. $\mathrm{pH}$ was also measured using the IQ Scientific "Dual Technology" $\mathrm{pH}$ meter in wells containing MRC-5 pulmonary fibroblasts exposed to media containing $2.5,25$ and $250 \mathrm{mg} \mathrm{mL}^{-1}$ of WTC dust incubated at $37^{\circ} \mathrm{C}$ with $5 \% \mathrm{CO}_{2}$ concentrations as well as $10 \% \mathrm{CO}_{2}$ concentrations over a $48 \mathrm{~h}$ period.

\subsection{CytoTox-ONETM Homogeneous Membrane Integrity Assay}

MRC-5 fibroblast cells were cultured in Eagle's Minimal Essential Media (MEM) and 10\% Fetal Bovine Serum (FBS). Following attachment, confluent cells were sub-cultured by scraping and reintroduced to MEM and $10 \% \mathrm{FBS} / \mathrm{PSKG}$. Cells were then plated in black flat bottom $300 \mu \mathrm{L}$ 96-well plate and incubated at $37^{\circ} \mathrm{C}$ for $48 \mathrm{~h}$ before being introduced to the different concentrations of WTC dust for $24 \mathrm{~h}$. After the $24 \mathrm{~h}$ incubation with WTC dust media, a 1:1 volume of CytoTox-ONE Reagent was added to the wells and incubated for 10 minutes. Stop solution was applied and the 96 well plate and was read and analyzed using the Bio-Tech's Synergy 2 multi plate reader at a wavelength of $540 \mathrm{~nm}$ and a bandwidth of $25 \mathrm{~nm}$ to quantify the conversion of Resozurin to fluorescent Resorufin. This conversion is directly proportional to the amount of $\mathrm{LDH}$ released from leaky cells into the surrounding medium upon cell lysis.

\subsection{ApoTox-Glo Triplex Assay ${ }^{\mathrm{T}}$}

Prior to beginning the assay, MRC-5 cell cultures were scraped, centrifuged and seeded in fresh MEM containing $10 \% \mathrm{FBS} / \mathrm{PSKG}$ media. The cells were then plated into 2 black $300 \mu \mathrm{L} 96$ well flat bottom plates and incubated for $24 \mathrm{~h}$ at $37^{\circ} \mathrm{C}$ and $5 \% \mathrm{CO}_{2}$. After a $24 \mathrm{~h}$ incubation period, the old media was aseptically removed and new WTC dust in media of 2.5, 25, $250 \mathrm{mg}$ $\mathrm{mL}^{-1}$ were added to the wells of both plates. Each plate was incubated for $24 \mathrm{~h}$ at $37^{\circ} \mathrm{C}$ and $5 \% \mathrm{CO}_{2}$ or $10 \%$ $\mathrm{CO}_{2}$. The day of the assay, the Viability/Cytotoxicity, reagents were added and plates were incubated for 45 minutes at $37^{\circ} \mathrm{C}$ at the corresponding $\mathrm{CO}_{2}$ concentrations of $5 \% \mathrm{CO}_{2}$ or $10 \% \mathrm{CO}_{2}$ for each plate. Fluorescence was measured at $360 \times 40 \mathrm{~nm}$ (viability) and $460 \times 40 \mathrm{~nm}$ (cytotoxicity) using a Bio-Tech's Synergy 2 multi plate reader. After reading, the Caspase-Glo® 3/7 Substrate was added to each test well of both 96 well plates and incubated for $45 \mathrm{~min}$ at $37^{\circ} \mathrm{C}$ and the corresponding $\mathrm{CO}_{2}$ concentration of $5 \% \mathrm{CO}_{2}$ or $10 \% \mathrm{CO}_{2}$. Luminescence was measured using the same multi plate reader mentioned previously.

\subsection{Statistical Analysis}

All data are expressed as mean \pm Standard Deviation (SD). For statistical analyses, one-way Analysis of Variance (ANOVA) with Student Newman Keul posthoc analysis were used to determine significant difference between exposure and control.

\section{RESULTS}

\section{1. pH Measurements and World Trade Center Dust}

Using the CytoTox-ONETM Homogeneous Membrane Integrity Assay, a positive dose-response relationship with increased cytotoxicity via membrane degradation in conjunction with increased WTC dust exposure is seen in Fig. 1. 
Michelle Hernandez et al. / OnLine Journal of Biological Sciences 12 (4) (2012) 142-148

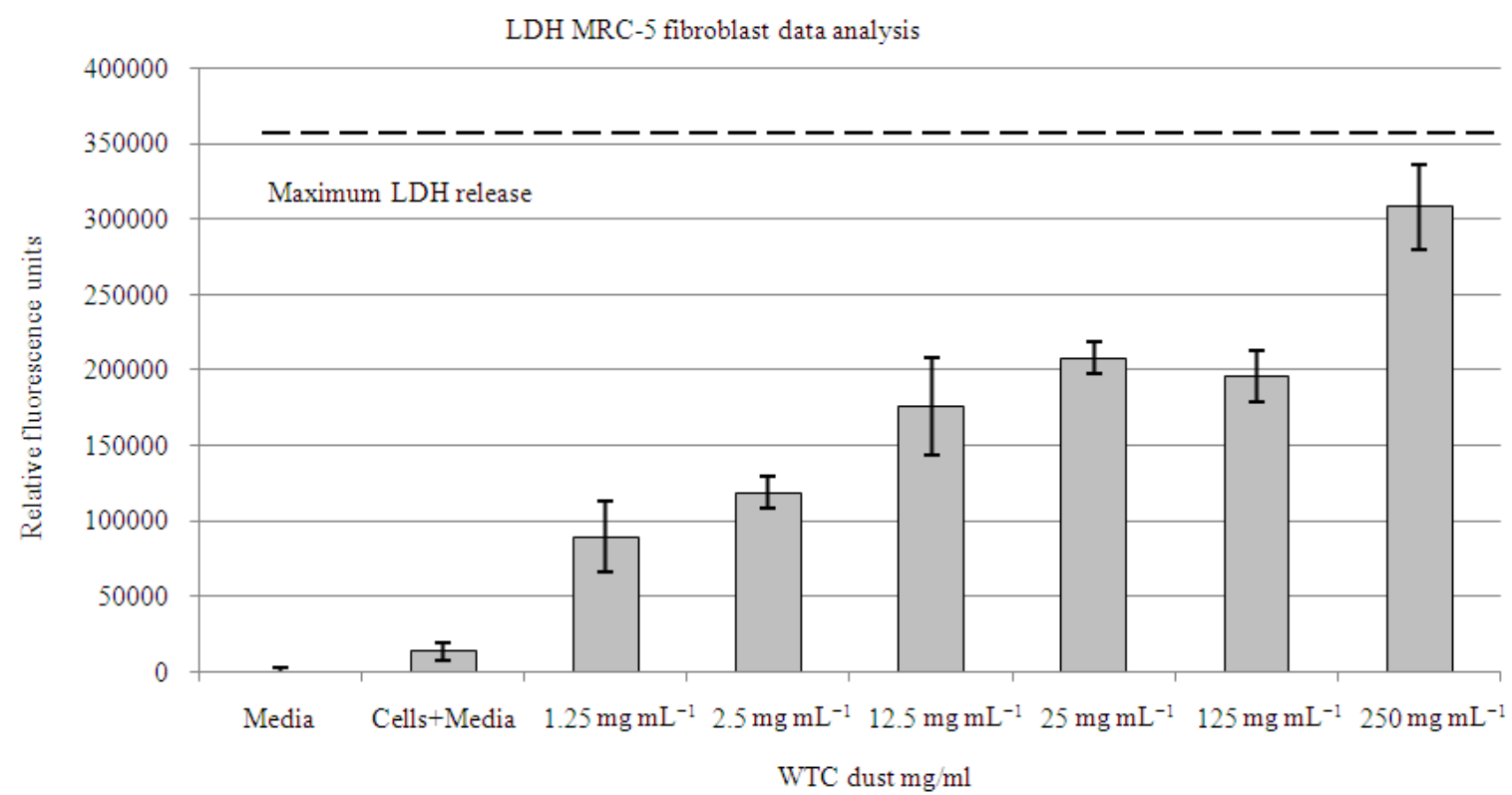

Fig. 1. Lactate dehydrogenase release from MRC-5 fibroblasts after treatments to different concentrations of WTC dust

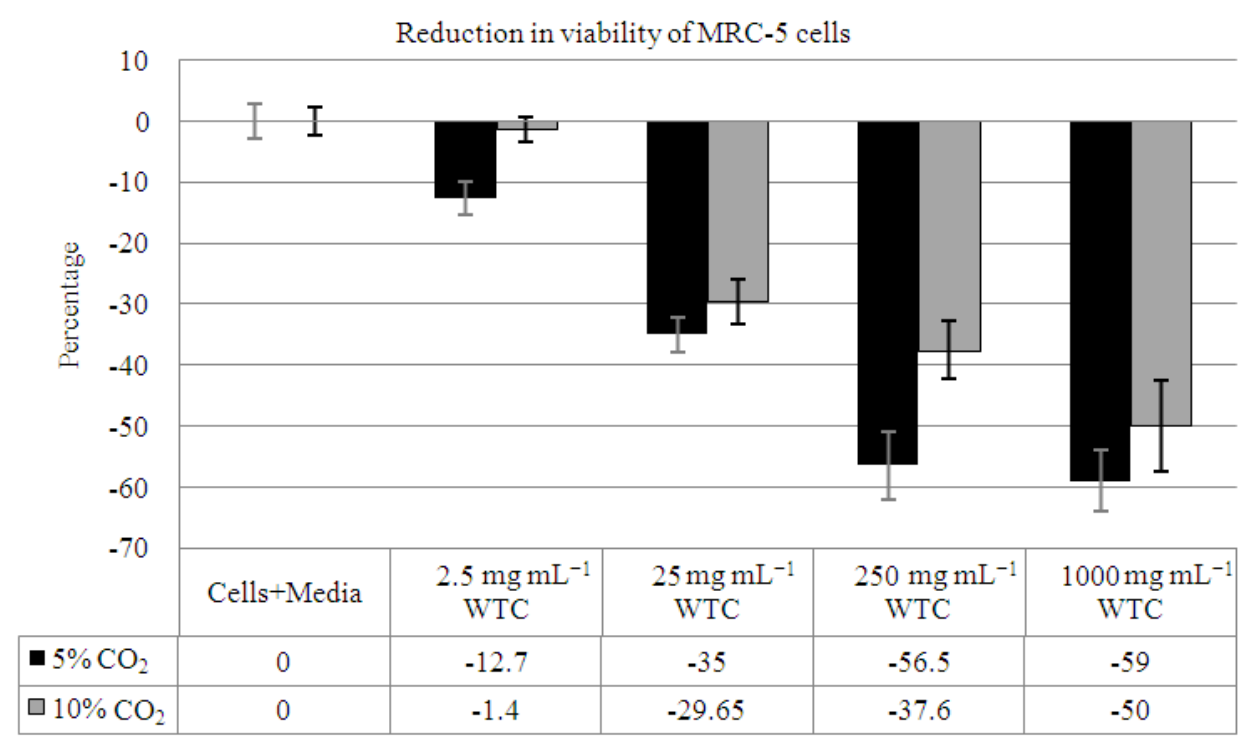

Fig. 2. Viability reduction of MRC-5 fibroblasts after treatments of different concentrations of WTC dust and different $\mathrm{CO}_{2}$ incubation concentrations. * indicates a p-value $<0.05$

The conversion amount of Resozurin to fluorescent Resorufin is directly proportional to the amount of LDH released into the surrounding medium. Maximum LDH release values were averaged and serve as the overall baseline for complete cell lysis. Figure 2 demonstrates a decrease in live cell protease activity, resulting in decreased cleavage of the GF-AFC substrate as WTC dust exposure concentrations increase. Increased viability between the two different $\mathrm{CO}_{2}$ concentrations may be due to an increased output of $\mathrm{H}^{+}$ions into the extracellular environment at an $\begin{array}{llll}\text { atmosphere } & \text { of } & 10 \% & \mathrm{CO}_{2} \text {. }\end{array}$ 


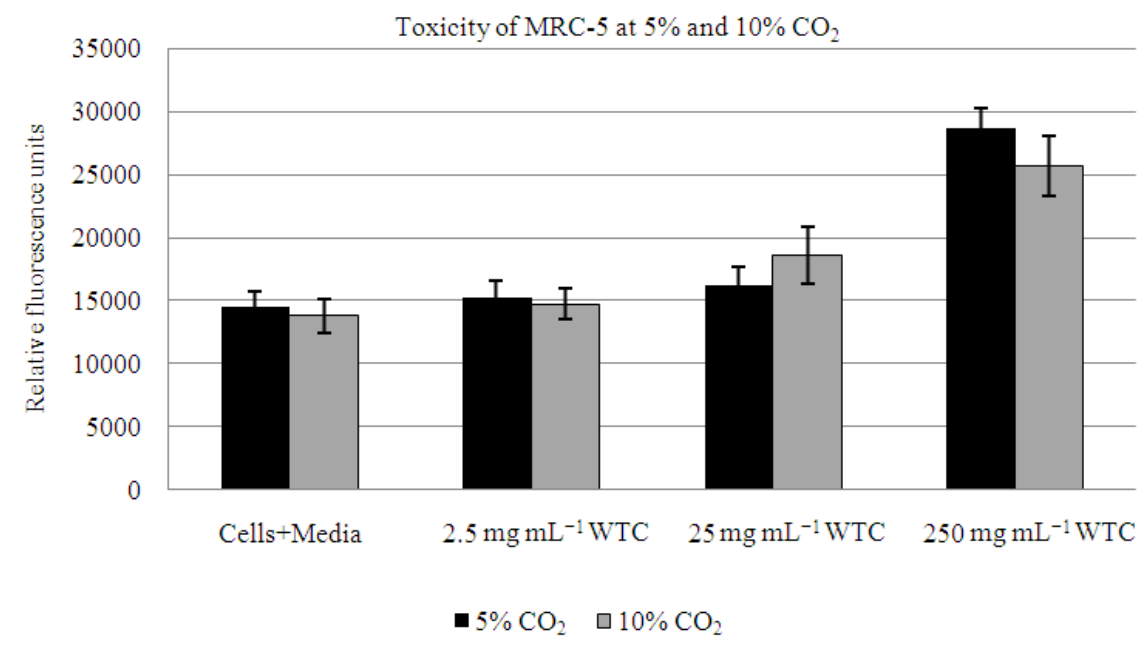

Fig. 3. Toxicity of MRC-5 fibroblasts after exposure to varying concentrations of WTC dust and different $\mathrm{CO}_{2}$ incubation concentrations. $*$ indicates a $\mathrm{p}$-value $<0.05$

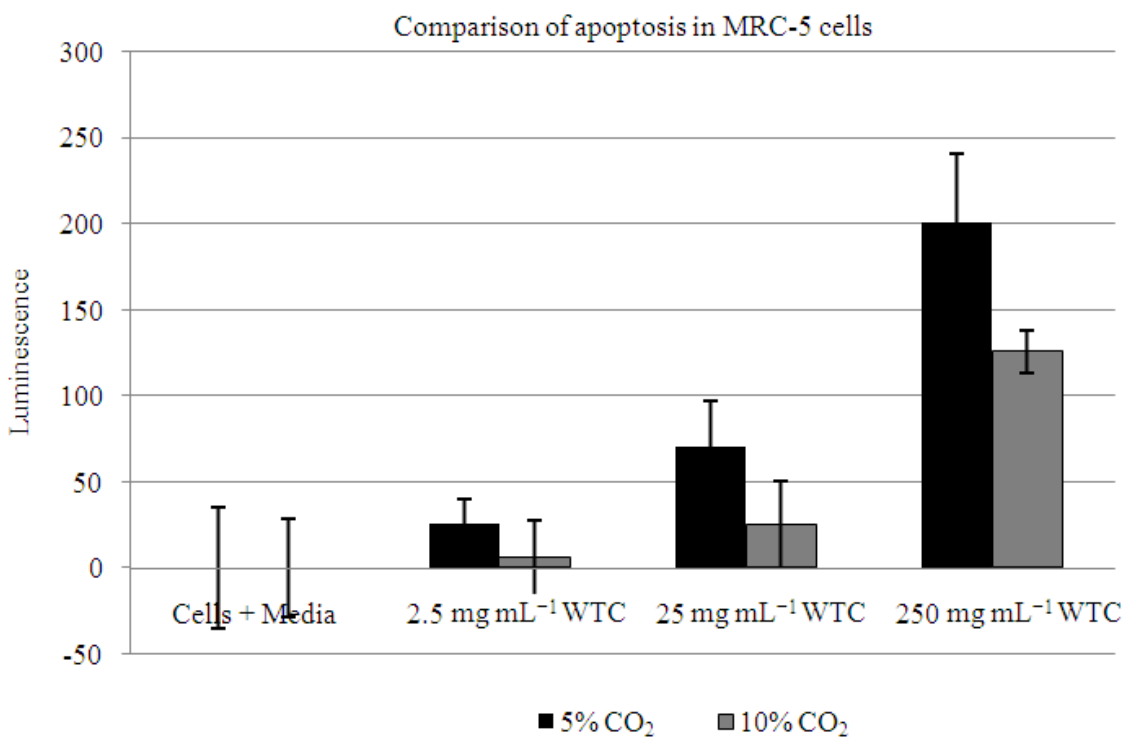

Fig. 4. Apoptotic activity of MRC-5 fibroblasts after exposure to varying concentrations of WTC dust and different $\mathrm{CO}_{2}$ incubation concentrations. $*$ indicates a $\mathrm{p}$-value $<0.05$

As toxicity increases, the amount of fluorescence produced by the cleavage of the bis-AAF-R110 substrate should also increase. The toxicity measured from the ApoTox-Glo Triplex Assay ${ }^{\mathrm{TM}}$ increased in a dose dependent manner regardless of $\mathrm{CO}_{2}$ concentration as illustrated in Fig. 3, indicating an increase in the production of dead-cell proteases that cleaved the bis-AAF-R110 substrate. Although toxicity is increased in both $\mathrm{CO}_{2}$ levels, $10 \% \mathrm{CO}_{2}$ exposure experienced decreased levels of toxicity as compared to the $5 \% \mathrm{CO}_{2}$ data set and warrants further investigation. Increase and decrease of apoptotic activity can be seen in Fig. 4. The measurement of luminescence using the ApoTox-Glo Triplex Assay ${ }^{\text {TM }}$ produced an increase in luminescence in conjunction with increased WTC dust exposure indicating increased activity in the cleavage of the tetrapeptide DEVD complex and the release of aminoluciferin. 
This in turn implies an increase in Caspase 3 and Caspase 7 activity in conjunction with increased WTC dust exposure. The data indicate that in comparison to the $10 \% \mathrm{CO}_{2}$ apoptosis values, the $5 \% \mathrm{CO}_{2}$ values increased anywhere from $33-77 \%$.

\section{DISCUSSION}

Previous experiments and current viability testing have demonstrated that MRC-5 cells experience a faster rate of proliferation in lower concentrations of WTC dust, suggesting that at lower concentrations cells are able to compensate for the change in $\mathrm{pH}$ regardless of $\mathrm{CO}_{2}$ incubation concentrations. Viability, toxicity and apoptosis measured using the ApoTox-Glo Triplex Assay $^{\mathrm{TM}}$ were all found to follow the same trend regardless of $\mathrm{CO}_{2}$ concentration exposure, along with decreased cell membrane integrity. In summary, the combination of these in vitro assays along with previous data have provided clear evidence of the impact WTC dust has on living systems. In conjunction with $\mathrm{pH}$ studies, increased levels of $\mathrm{CO}_{2}$ exposure show a possible mechanism by which an alkaline extracellular environment can be mitigated by increased $\mathrm{CO}_{2}$ exposure.

Figure 1 and 3 suggest that WTC dust is cytotoxic at many levels and induces significant fibroblast lysis. Apoptosis includes the cell mediated death of a cell. The many factors at play with apoposis include Caspases 3 and 7 , both of which are involved in the intrinsic and extrinsic apoptotic pathways. Caspases are known to inactivate enzymes involved in DNA repair (PARPpolymerase repairer), breakdown nuclear and cytoskeleton structures inciting the occurrence of blebbing and fragmenting DNA via caspase activated DNase (CAD) (Smulson et al., 2000; Cruchten and Broeck, 2002; Janeway et al., 2005). The extrinsic MAPK pathway is an example that includes the cleavage of Caspase 3, the activation of Caspases 6 and 7 and the cleavage of Inhibitor of Caspase Activated DNase (ICAD) initiating the cleavage of DNA via active DNases (Janeway et al., 2005). Indications of genotoxicity on a molecular level in humans may be a result of apoptotic dysfunction. Under the premise that acids degrade proteins and bases degrade lipids, it is feasible to conclude, along with experimental data, that the alkaline nature of the WTC dust at higher concentrations contributed in part to the decreased membrane integrity of MRC-5 lung fibroblasts.

Table 1a illustrates the establishment of the WTC dust $\mathrm{pH}$ in media. The $\mathrm{pH}$ of the $10 \% \mathrm{CO}_{2}$ concentration comes close to our physiological $\mathrm{pH}$ of 7.4 and is representative of normal cell membrane environment. Normal membrane as it would be affected by WTC dust, thus, can be seen in Table $\mathbf{1 b}$. This could be one of the factors as to why we see increased viability and why $10 \% \mathrm{CO}_{2}$ may help to mitigate the alkaline effects of WTC dust better. These results are also true for toxicity and apoptotic readings as well. Although the contents of the WTC dust have been characterized, toxicity testing on a larger scale has yet to yield any results.

Table 1a. Mean $\mathrm{pH}$ measurements of different concentrations of WTC dust in $10 \%$ FBS $1 \%$ PSKG media only at 5 and $10 \% \mathrm{CO}_{2}$

\begin{tabular}{lllll}
\hline & $10 \% \mathrm{FBS}$ & $2.5 \mathrm{mg} \mathrm{mL}^{-1}$ & $25 \mathrm{mg} \mathrm{mL}^{-1}$ & $250 \mathrm{mg} \mathrm{mL}^{-1}$ \\
& PSKG media & WTC media & WTC media & 8.1 \\
\hline $5 \% \mathrm{CO}_{2}$ & 7.3 & 7.7 & 7.9 & 8.2 \\
$10 \% \mathrm{CO}_{2}$ & 7.4 & 7.8 & 7.9 & media \\
\hline
\end{tabular}

Table 1b. pH measurements of WTC dust and MRC-5 fibroblasts at three different time points and at 5 and $10 \% \mathrm{CO}_{2}$. Standard error not shown $<5 \%$

\begin{tabular}{|c|c|c|c|}
\hline Control Media and MRC-5 & $\mathrm{pH}$ at $0 \mathrm{~h}$ & $\mathrm{pH}$ at $24 \mathrm{~h}$ & $\mathrm{pH}$ at $48 \mathrm{~h}$ \\
\hline $5 \% \mathrm{CO}_{2}$ & 7.5 & 7.4 & 7.4 \\
\hline $10 \% \mathrm{CO}_{2}$ & 7.4 & 7.2 & 7.1 \\
\hline $2.5 \mathrm{mg} \mathrm{mL}^{-1}$ WTC dust and MRC-5 & $\mathrm{pH}$ at $0 \mathrm{~h}$ & $\mathrm{pH}$ at $24 \mathrm{~h}$ & $\mathrm{pH}$ at $48 \mathrm{~h}$ \\
\hline $5 \% \mathrm{CO}_{2}$ & 7.7 & 7.8 & 7.7 \\
\hline $10 \% \mathrm{CO}_{2}$ & 7.7 & 7.5 & 7.3 \\
\hline $25 \mathrm{mg} \mathrm{mL}^{-1}$ WTC dust and MRC-5 & $\mathrm{pH}$ at $0 \mathrm{~h}$ & $\mathrm{pH}$ at $24 \mathrm{~h}$ & $\mathrm{pH}$ at $48 \mathrm{~h}$ \\
\hline $5 \% \mathrm{CO}_{2}$ & 7.8 & 7.9 & 7.9 \\
\hline $10 \% \mathrm{CO}_{2}$ & 7.8 & 7.6 & 7.5 \\
\hline $250 \mathrm{mg} \mathrm{mL}^{-1} \mathrm{WTC}$ dust and MRC-5 & $\mathrm{pH}$ at $0 \mathrm{~h}$ & $\mathrm{pH}$ at $24 \mathrm{~h}$ & $\mathrm{pH}$ at $48 \mathrm{~h}$ \\
\hline $5 \% \mathrm{CO}_{2}$ & 8.1 & 7.9 & 7.9 \\
\hline $10 \% \mathrm{CO}_{2}$ & 7.9 & 7.7 & 7.5 \\
\hline
\end{tabular}


There are many other toxic components including hexavalent chromium and antimony that have not been studied in the context of the WTC dust. Low levels of cellular damage caused by silica, asbestos and other damaging agents can prevent apoptosis from occurring and in turn can cause intracellular material destined for outside of the cell to be released inside the cell provoking an inflammatory response (Thomas et al., 2007). If the apoptotic signaling pathway becomes slightly damaged or altered, a continuous proinflammatory response could result and may be linked to the constant pro inflammatory symptoms experienced by those who worked and lived within the WTC site.

\section{CONCLUSION}

Studies have found that workers and residents who currently work or reside within a 1 mile radius of the WTC site are still being affected significantly by lower respiratory symptoms (Lin et al., 2010). In a large sample population of New York City firefighters and FDNY workers, the average Forced Expiratory Volume (FEV) decreased significantly for all workers without recovery over a six year period (Aldrich et al., 2010). Many mechanisms exist to help clear the pulmonary system of unwanted particulate matter including the mucociliary escalator, phagocitosis by macrophages via the mucociliary escalator, lymphatic system and circulatory system (Gross and Hatch, 1963; Isawa et al., 1984). If any of these mechanisms are compromised, the function or dysfunction of the corresponding mechanisms can result in systemic complications as well as increased risk of infection/ recurrent infections (Gross and Hatch, 1963; Isawa et al., 1984). Due to its heterogeneous nature, WTC particulate matter clearance also relies on other factors which include mechanical transport and chemical/receptor binding that assist in pulmonary clearance. When hindered, these activate an immune response causing the release of Reactive Oxygen Species (ROS) as well as proteases.

Overall, the components that make up the dust may have an additive effect, even if the components on their own are non-reactive or non-toxic. A toxicological profile when combined with another can alter the properties of the original, making the combined profile more toxic than the individual effects would be (Donaldson et al., 1998; Ferin, 1994). There are limitations as to what can be done in vitro, more particularly testing involving the use of fluorescence probes. Although the use of a Triplex Assay allows for a more convenient way to measure viability, toxicity and apoptosis, apoptotic cells usually retain their cellular membrane integrity until the later stages of apoptosis, although these cells are already "dead" in regards to usual function for the cell type and further proliferation. Further studies investigating protein expression as well as genotoxic effects are warranted and should be conducted for a better understanding behind the molecular mechanisms by which WTC dust inhibits normal cellular processes that result in cellular damage.

\section{ACKNOWLEDGEMENT}

We express our appreciation to Dr. Lioy of Rutgers University for providing us with a sample of World Trade Center dust.

\section{REFERENCES}

Aldrich, T.K., J. Gustave, C.B. Hall, H.W. Cohen and M.P. Webber et al., 2010. Lung function in rescue workers at the world trade center after 7 years. New England J. Med., 362: 1263-1272. DOI: 10.1056/NEJMoa0910087

Chen, L.C. and G. Thurston, 2002. World trade center cough: Lessons learned. Lancet, 360: s37-s38.

Cruchten, S.V. and W.V.D. Broeck, 2002. Morphological and biochemical aspects of apoptosis, oncosis and necrosis. Anatomia, Histologia, Embryologia. J. Vet. Med., 31: 214-223. DOI: 10.1046/j.1439-0264.2002.00398.x

Donaldson, K., X.Y. Li and W. MacNee, 1998. Ultrafine (nanometre) particle mediated lung injury. J. Aerosol Sci., 29: 553-560. DOI: 10.1016/S00218502(97)00464-3

Ferin, J., 1994. Pulmonary retention and clearance of particles. Toxicol. Lett., 72: 121-125. DOI: 10.1016/0378-4274(94)90018-3

Gross, P. and T. Hatch, 1963. Pulmonary clearance: Its mechanism and its relation to pulmonary disease. J. Occupat. Med., 5: 191-194. PMID: 13950780

Isawa, T., T. Teshima, T. Hirano, A. Ebina and M. Motomiya et al., 1984. Lung clearance mechanisms in obstructive airways disease. J. Nucl. Med., 25: 447-54. PMID: 6544816

Izbicki, G., R. Chavko, G.I. Banauch, M.D. Weiden and K.I. Berger et al., 2007. World trade center "sarcoidlike" granulomatous pulmonary disease in new york city fire department rescue workers. Chest, 131: 1414-1423. DOI: $10.1378 /$ chest.06-2114 
Janeway, C.A., P. Travers, M. Walport and M.J. Schlomchik, 2005. Immunobiology. 1st Edn., Garland Science, New York.

Lin, S., R. Jones, J. Reibman, D. Morse and S.A. Hwang, 2010. Lower respiratory symptoms among residents living near the World Trade Center, two and four years after 9/11. Int. J. Occup. Environ. Health,16: 44-52. PMID: 20166318

Lioy, P.J., C.P. Weisel, J.R. Millette, S. Eisenreich and D. Vallero et al., 2002. Characterization of the dust/smoke aerosol that settled east of the World Trade Center (WTC) in lower Manhattan after the collapse of the WTC 11 September 2001. Environ. Health Perspect., 110: 703-714.

McGee, J.K., L.C. Chen, M.D. Cohen, G.R. Chee and C.M. Prophete et al., 2003. Chemical analysis of World Trade Center fine particulate matter for use in toxicologic assessment. Environ. Health Perspect., 111: 972-980.

Pauly, J.L., S.J. Stegmeier, H.A. Allaart, R.T. Cheney and P.J. Zhang et al., 1998. Inhaled cellulosic and plastic fibers found in human lung tissue. Cancer Epidemiol. Biomarkers Prevent., 7: 419-428.
Smulson, M.E., C.M. Simbulan-Rosenthal, A.H. Boulares, A. Yakovlev and B. Stoica et al., 2000. Roles of poly(ADP-ribosyl)ation and PARP in apoptosis, DNA repair, genomic stability and functions of p53 and E2F-1. Adv. Enzyme Regul., 40: 183-215. PMID: 10828352

Terminella, C., K. Tollefson, J. Kroczynski, J. Pelli and M. Cutaia, 2002. Inhibition of apoptosis in pulmonary endothelial cells by altered $\mathrm{pH}$, mitochondrial function and ATP supply. Am. J. Physiol.-Lung Cellular Mol. Physiol., 283: L1291L1302. DOI: 10.1152/ajplung.00246.2001

Thomas, J.K., A.G. Richard and A.O. Barbara, 2007. Kuby Immunology. 6th Edn., Sara Tenny, pp: 574.

Thurston, G.D. and L.C. Chen, 2002. Risk communication in the aftermath of the world trade center disaster. Am. J. Indus. Med., 42: 543-544. DOI: 10.1002/ajim.10163 